\title{
Saúde pública como precursor de uma nova era para a população brasileira
}

\author{
Liliani Travezani Martins \\ Enfermeira pelo Centro Universitário São Camilo- ES \\ Especialista em Enfermagem do Trabalho e Gestão em Saúde Pública e Meio Ambiente (UCAM) \\ Acadêmica do curso de Farmácia da Faculdade Pitágoras (Campus - Guarapari -ES) \\ $\square$ lilimartins12@gmail.com
}

Recebido em 11 de abril de 2017

Aceito em 01 de setembro de 2017

\section{Resumo:}

O artigo apresenta as mudanças ocorridas no decorrer da história da saúde pública com enfoque nas décadas de 1980 e 1990. A partir hipótese que as modificações ocorridas no decorrer da história da saúde pública brasileira trouxeram benefícios à população em geral, ou seja, todos têm acesso à saúde independente do lugar em que vive, sexo, idade, raça, etnia e condições socioeconômicas. Este estudo é uma revisão bibliográfica teórica que utilizou fontes como: livros de instituições de ensino superior, artigos científicos, endereços eletrônicos como o Scielo (Scientific Electronic Library Online), Google acadêmico, site do Ministério da saúde e da Fundação Nacional de Saúde. O intuito da busca bibliográfica teórica foi desvendar os caminhos percorridos na saúde pública para observar as mudanças da mesma até hoje. Sendo assim, torna-se visível de acordo com as pesquisas que a saúde pública evolui para beneficiar a população em geral, ou seja, que todos os cidadãos tenham uma saúde de qualidade e prestada com a dignidade merecida. Porém percebe-se uma diferença marcante entre a concepção teórica do sistema único de saúde (SUS) e a sua real aplicação e desempenho para a população em geral. Esta diferença pode ser resultante de dificuldades de articulações entre as esferas.

Palavras-chave: Saúde Pública, História, Assistência à Saúde.

\section{Public health as a harbinger of a new age for the Brazilian population}

\begin{abstract}
:
This article presents the changes that occurred during the history of public health with focus in the 1980s and 1990s. Based on the hypothesis that the changes that occurred during the history of Brazilian public health brought benefits to the population in general, that is, all have Access to health independent of where they live, sex, age, race, ethnicity and socioeconomic conditions. This study is a theoretical literature review that used sources such as: books of higher education institutions, scientific articles, electronic addresses such as Scielo (Scientific Electronic Library Online), Google academic, website of the Ministry of Health and the National Health Foundation. The purpose of the theoretical bibliographic search was to unveil the paths covered in public health to observe the changes of the same until today. Thus, it becomes visible according to research that public health evolves to benefit the population in general, that is, that all citizens have a quality health and provided with the dignity deserved. However, there is a marked difference between the theoretical conception of the single health system (SUS) and its real application and performance for the general population. This difference may be due to difficulties of joints between the spheres. Keywords: Public Health, History, Health Care.
\end{abstract}




\title{
Salud pública como precursor de una nueva era para la población brasileña
}

\begin{abstract}
Resumen:
El artículo presenta los cambios ocurridos en el transcurso de la historia de la salud pública con enfoque en las décadas de 1980 y 1990. A partir de hipótesis que las modificaciones ocurridas en el transcurso de la historia de la salud pública brasileña trajeron beneficios a la población en general, o sea, Acceso a la salud independiente del lugar en que vive, sexo, edad, raza, etnia y condiciones socioeconómicas. Este estudio es una revisión bibliográfica teórica de que utilizó fuentes como: libros de instituciones de enseñanza superior, artículos científicos, direcciones electrónicas como el SciELO (Scientific Electronic Library Online), Google académico, sitio del Ministerio de Salud y de la Fundación Nacional de Salud. El objetivo de la búsqueda bibliográfica teórica fue desvelar los caminos recorridos en la salud pública para observar los cambios de la misma hasta hoy. Por lo tanto, se hace visible de acuerdo con las investigaciones que la salud pública evoluciona para beneficiar a la población en general, es decir, que todos los ciudadanos tengan una salud de calidad y prestada con la dignidad merecida. Pero se percibe una diferencia marcada entre la concepción teórica del sistema único de salud (SUS) y su real aplicación y desempeño para la población en general. Esta diferencia puede deberse a dificultades de articulaciones entre las esferas.
\end{abstract}

Palabras clave: Salud Pública, Historia, Asistencia sanitaria.

\section{INTRODUÇÃO}

Apresentamos a história da saúde pública como marco importante na saúde da população, tendo como objetivo principal caracterizar as mudanças ocorridas no decorrer da história da saúde pública brasileira com enfoque para década de 1980 e 1990. Avaliando como as transformações de cada período influenciaram a saúde da população em geral. 0 estudo tem como pressuposto a seguinte hipótese: as modificações ocorridas no decorrer da história da saúde pública trouxeram benefícios à população em geral, ou seja, todos têm acesso à saúde independente do lugar em que vive, sexo, idade, raça, etnia e situação sócio econômica.

"Durante os últimos 30 anos a situação da saúde pública, no Brasil e no mundo, evoluiu rápida e profundamente [...]" (SILVA, 1996, p. 503). Sendo assim, é possível observar que a mesma teve que se moldar para atender a população.

“[...] o marco inicial da saúde pública ocorre com revolução industrial, iniciada na segunda metade do século XVIII, veio determinar profunda repercussão na estrutura social da humanidade e sobre a saúde coletiva [...]" (MINISTÉRIO DA SAÚDE, 1979, p. 1). Ou seja, como as pessoas se deslocaram da área rural para a cidade e com acúmulo e/ou concentração desses trabalhadores, observou-se a necessidade de mudanças nas ações de saúde pública. De 
encontro à nova realidade o diretor geral da saúde pública do Governo Federal iniciou em 1903, no Rio de Janeiro, uma luta para erradicar epidemias. Lançou importantes expedições científicas, que possibilitaram maior conhecimento sobre a realidade sanitária do interior do país que contribuíram para a ocupação da região (BRASIL, 2006). Logo a diante, em 1908 Oswaldo Cruz reformou o Código Sanitário e reestruturou todos os órgãos de saúde e higiene do país. Isso porque, a família real mudou-se para o Brasil neste mesmo ano (1908). Daí surge à necessidade da organização de uma estrutura sanitária mínima, capaz de dar suporte ao poder que se instalava na cidade do Rio de Janeiro (POLIGNANO, 2008).

\begin{abstract}
A primeira comissão formada da Fundação Rockefeller chegou ao Brasil em 1915, formada por William Henry Welch (bacteriologista) e Wicklille Rose (Diretor da Iternacional Health Commission). No ano seguinte chegou ao país uma segunda comissão, desta vez formada pelos médicos Richard M. Pearce (diretor da divisão de Educação Médica), John A. Ferrele (assistente da Comissão Sanitária Internacional) e o major Baileey K. Ahsfor (Comissão de Saúde do Exército dos Estados Unidos) (FARIA, 1995, p. 109-110).
\end{abstract}

Objetivo desses sanitaristas era pesquisar o contexto politico e cultural e as condições sanitárias do país, para estabelecer os moldes de sua atuação para os brasileiros e exigir que o Estado exercesse maior controle sobre as políticas sanitaristas nas regiões brasileiras.

Dos movimentos organizados surge a Previdência Social no Brasil em 1923 ainda no século passado quando os movimentos trabalhistas urbanos criam as Caixas de Aposentadorias e Pensões (CAPS). Este decreto legislativo ficou conhecido como Lei Elói Chaves (Decreto 4.628, de 24 de janeiro de 1923) criando as Caps. Que conseqüentemente são transformados em Institutos de Aposentadorias e Pensões (IAPS), com forte peso dos sindicatos de trabalhadores e entidades patronais, em relação ao governo federal, na sua organização e gestão, inclusive, da assistência médico-hospitalar (JUNIOR; JUNIOR, 2006 MATOS; SANTOS, 2007). Tais institutos foram o IAPTEC (para trabalhadores em transporte e cargas), IAPC (para os comerciários), IAPI (industriários), IAPB (bancários), IAPM (marítimos e portuários) e IPASE (servidores públicos) (JUNIOR; JUNIOR, 2006). Só tinham direito aos benefícios, ou seja, a saúde os trabalhadores que contribuíam para a Previdência aqueles "com carteira assinada". 
Em meio a essas mudanças, veio a ser instituído o Ministério da Saúde no dia 25 de julho de 1953, com a Lei oo 1.920 (Lei № 1.920, de 25 de julho de 1953) sob a influência do Plano Solte formulado no mandado do General Eurico Gaspar Dutra.

(...) 1974 surge o PPA - Plano de Pronta Ação e o FAS - Fundo de Apoio ao Desenvolvimento Social para enfrentar a crescente demanda curativa. Foi um conjunto de ações que desburocratizou o atendimento de urgência ao segurado e permitiu o atendimento ambulatorial a toda a população nos casos de urgência. Foi referência porque foi o início da universalização do atendimento (JUNIOR; JUNIOR, 2006, p. 15).

O governo cria em 1977 o Sistema Nacional de Previdência e Assistência Social (SINPAS) através da Lei 6.439/77.12. Que é composto pelas seguintes instituições: 1 ) Instituto Nacional de Previdência Social - INPS; 2) Instituto Nacional de Assistência Médica da Previdência Social - INAMPS; 3) Fundação Legião Brasileira de Assistência - LBA; 4) Fundação Nacional do Bem Estar do Menor - FUNABEM; 5) Empresa de Processamento de Dados da Previdência Social - DATAPREV; 6) Instituto de Administração Financeira da Previdência e Assistência Social - IAPAS; e 7) a Central de Medicamentos - CEME. (Lei № 6.439, de $1^{\circ}$ de setembro de 1977).

“[...] A criação do CONASP se deu no ano de 1983 com a criação do Programa de Ações Integrada de Saúde (PAIS), que visava universalização do atendimento e acesso da população aos serviços de diferentes níveis [...]" (MATOS; SANTOS, 2007, p.8).

Deste modo foi concebido um subsistema de Atenção Médica Supletiva composta de cinco modalidades assistenciais: medicina de grupo, cooperativas médicas, auto-gestão, seguro-saúde e plano de administração (POLIGNANO, 2008). O subsistema de atenção médica-supletiva cresce vertiginosamente na década de 1980.

Para Rizotti (2001), os anos 1980 seriam identificados como a década perdida, isso por causa do período recessivo que o país conheceu entre 1981 e 1983. Ainda neste contexto de grave crise econômica e atividade industrial no país caindo. Acrescentou um grande número de desempregados e a defasagem do valor do real pago aos trabalhadores. Esse 
contexto político e econômico da primeira metade dos anos 1980 recolocou a questão social na agenda pública da sociedade brasileira.

Até a década de 1980, o sistema de saúde era centralizado. Já em 1987 cria-se o Sistema Unificado e Descentralizado de Saúde (SUDES). Foi a partir daí que a saúde pública sofre um salto para as mudanças que hoje conhecemos. No final da década de 1980 em diante, foi criada a Constituição Federal de 1988, que determinou ser dever do Estado garantir saúde a toda a população. A partir da constituição criou-se o Sistema Único de Saúde (SUS) (FINKELMAN, 2002).

Em 1990, o Congresso Nacional aprovou a Lei Orgânica da Saúde que detalha o funcionamento do Sistema e definiu seus objetivos, competências e atribuições; princípios e diretrizes; organização, direção e gestão (Lei № 8.080 de 19 de setembro de 1990). Polignano (2008), cita que no período de 1991 a 1994, com a eleição do Fernando Collor de Mello é implementada com toda a força uma política neoliberal e privatizante, com um discurso de reduzir o estado ao mínimo que acaba atingindo todos os setores do governo, principalmente o da saúde. Mas é neste período que o governo começa a editar as Normas Operacionais Básicas (NOBs). Ou seja, essas normas concretizam o processo de descentralização do SUS, reorienta o modelo assistencial, favorecendo a ampliação do acesso aos serviços de saúde, a participação da população e a melhoria do fluxo de recursos financeiros destinados à saúde. Portanto, os recursos seriam administrados de acordo com a necessidade dos municípios.

\section{METODOLOGIA}

Trata-se de um estudo de revisão bibliográfica teórica, ao qual utilizou-se como fonte: livros de instituições de ensino superior, artigos científicos, endereços eletrônicos como: Scielo (Scientific Electronic Library Online), Google acadêmico, revistas cientificas, site do Ministério da saúde e da Fundação Nacional de Saúde. O Estudo foi iniciado no primeiro semestre de 2012 e concluído em meados de setembro do mesmo ano, tendo como 
palavras chaves: saúde pública, história, assistência à saúde. Que aborda a cronologia e a evolução da saúde pública com foco para as décadas de 1980 e 1990.

Os dados foram analisados e organizados de acordo com os materiais publicados nos últimos trinta e oito anos. Após, o levantamento dos dados, optou-se pelo método de revisão bibliográfica. Que é o processo de levantamento e análise do que já foi publicado sobre o tema de pesquisa escolhido, permitindo efetuar um mapeamento do que já foi escrito e de quem já escreveu algo sobre o tema da pesquisa (MORESI, 2003). De acordo com Lakatos e Marconi (1982), a pesquisa pode ser considerada como um procedimento formal e reflexivo, que requer um tratamento científico, onde através de levantamento de dados constitui-se em analisar e apurar os dados obtidos. Sendo assim, a mesma pode ser considerada como primeiro passo para toda pesquisa científica.

Os critérios de inclusão utilizados foram artigos sobre saúde pública na década de 1980 e 1990, história da saúde pública no Brasil e evolução institucional. Já os de exclusão estão associados á artigos que não contemple saúde publica e a década de 1980 e 1990 e Indicadores de mortalidade e morbidade.

\section{RESULTADOS E DISCUSSÃO}

No decorrer de todas as pesquisas e análises foi possível observar que a saúde pública se faz presente desde o inicio dos tempos segundo a datação ocidental (a.C/d.C.), pois até na Bíblia são apresentadas passagens em que Deus dá instruções a Moisés para manter seu povo saudável. Naquela época era a lepra a principal doença acometer os povos e no capítulo 14 do livro Levítico se descreve o que foi feito para cuidar das pessoas que haviam adquirido lepra. Ou seja, nota-se que a saúde está presente na sociedade desde os tempos mais remotos (BÍBLIA CATÓLICA, Cap. 14, V. 2 à 32).

Contudo, foi necessário criar novas abordagens de saúde para população. Com a revolução industrial, já no período moderno, as mudanças começam a tomar formas significativas. Há um aglomerado de pessoas chegando para trabalhar nas fábricas. E as cidades não apresentavam estruturas adequadas para abrigar essa nova população e nem o lixo produzido por ela. Essa desordem migratória do campo para a cidade e a falta de 
estrutura dessa última para receber os migrantes inicia um processo de adoecimento populacional.

Essa desordem passa a ter a atenção do Estado e a receber melhorias com a chegada de família real. A partir de 1808 o quadro da saúde brasileira modifica-se, pois se faz premente uma estrutura de saúde para adequar o país as necessidades da realeza.

As primeiras comissões de saúde são estabelecidas com o propósito de estudar nossas características social, econômica e cultural para estabelecer pontos de melhorias.

Nesse avanço cronológico surge a ação do poder público que cria o Instituto Nacional de Previdência Social. Que mais tarde seria chamado de Instituto Nacional de Assistência Médica da Previdência Social (INAMPS). Onde somente os trabalhadores com carteira assinada tinham acesso à saúde.

Com a crise de financiamento da Previdência, que começa a se manifestar a partir de meados da década de 70, o INAMPS adota várias providências para racionalizar suas despesas e começa, na década de 80, a "comprar" serviços do setor público (redes de unidades das Secretarias Estaduais e Municipais de Saúde), inicialmente por meio de convênios. A assistência à saúde prestada pela rede pública, apesar do financiamento do INAMPS apenas para os seus beneficiários, preservou o seu caráter de universalidade da clientela (MINISTÉRIO DA SAÚDE, 2002.p.13).

E foi nesta época que as empregadas domésticas e os trabalhadores rurais incluindo os autônomos foram beneficiados com a assistência a saúde.

Como nenhum sistema é perfeito e como foi descrito no parágrafo acima o INAMPS começa a declinar e já no fim da década de 1980 o INAMPS e o governo federal por meio de um acordo implantam o Sistema Unificado e Descentralizado de Saúde (SUDS). Que vai dá seqüência ao Sistema Único de Saúde (SUS). Conforme descrição apresentada observa-se que foi em 1980 e 1990 que a saúde deu um salto, ou seja, foi a partir daí que as mudanças ocorreram. O modelo centralizador deu lugar ao processo de descentralização do SUS. O SUS traz uma proposta nova para a saúde da população, principalmente pelos seus princípios doutrinários que são: universalidade, equidade, integralidade, hierarquização, participação popular e descentralização. Mostra que o governo começa a criar consciência a respeito do que a saúde representa para população. Isso fica claro no processo de construção do Sistema Único de Saúde (SUS), pois houve a necessidade de reorientar as práticas de saúde à medida 
que se definem as questões macroestruturais do sistema, pois ficam evidentes as lacunas existentes na assistência e no próprio sistema de saúde (MOTA; SCHRAIBER, 2011). Constatase que o setor da saúde hoje vive um momento peculiar. O Sistema Único de Saúde (SUS) constitui um moderno modelo de organização dos serviços de saúde que tem como uma de suas características primordiais valorizar o nível municipal (WALDMAN, 1998).

Esse novo paradigma compete ao gestor à visão de saúde integral e com equidade, em que o modelo econômico se subordine a saúde como um bem maior, que deve ser compartilhado pela coletividade (MATOS; SANTOS, 2007). Portanto, as atribuições dos gestores do SUS nos três níveis de governo são fazer com que o SUS seja implantado e funcione adequadamente dentro das diretrizes doutrinárias, da lógica organizacional e seja operacionalizado dentro dos princípios anteriormente citados (SOUZA, 2002).

\begin{abstract}
Os gestores nas três esferas do Governo, são, nível municipal, estadual e federal. Nos municípios, os gestores são as secretarias municipais de saúde ou as prefeituras, sendo responsáveis pelas mesmas, os respectivos secretários municipais e prefeitos. Nos estados, os gestores são os secretários estaduais de saúde e no nível federal o Ministério da Saúde. A responsabilidade sobre as ações e serviços de saúde em cada esfera de governo, portanto, é do titular da secretaria respectiva, e do Ministério da Saúde no nível federal. No nível municipal, cabe aos gestores programar, executar e avaliar as ações de promoção, proteção e recuperação da saúde. Isto significa que o município deve ser o primeiro e o maior responsável pelas ações de saúde para a sua população (MINISTÉRIO DA SAÚDE, 1990, p.6).
\end{abstract}

No decorrer da explanação obtém-se a seguinte resposta: as mudanças ocorridas foram simplesmente para beneficiar todos em geral, e cada dia o sistema evolui para atender todos os cidadãos com a dignidade merecida. Mas, é necessário que ainda haja mudanças. O SUS Não é um sistema de saúde perfeito, mas em busca da perfeição para desenvolver técnicas de saúde com qualidade para atender todos os que buscam e/ou precisam de atendimento à saúde.

\title{
CONSIDERAÇõES FINAIS
}

O presente artigo caracterizou as mudanças ocorridas na história da saúde pública e sua evolução. Durante a pesquisa foi possível constatar que a saúde está em constate 
mudança produzindo reações na vida da população. A saúde pública já sofreu varias modificações até hoje e há de sofrer inúmeras outras para atender as mudanças sociais e dos fatores transformadores dos envolvidos de forma passiva ou ativa neste contexto.

Percebe-se com clareza, que logo no começo de sua estrutura a saúde pública beneficiava apenas parte da sociedade, ou seja, os que tinham condições de pagar por ela. Seja através da Previdência Social ou não.

Quando Oswaldo Cruz assume a Direção Geral da Saúde Pública do Governo Federal essas mudanças são perceptíveis. Contudo, o governo acaba observando a necessidade de mudanças e cria a Previdência Social, que se dá em um longo percurso. Indo adiante importantes ações que resultam na criação do Sistema Único de Saúde (SUS).

O Sistema Único de Saúde (SUS) pode ser definido como o conjunto de ações e serviços de saúde distribuídos sobre o território brasileiro para atender a população e um grande marco na evolução da saúde pública.

Também se constata que foi no período compreendido entre 1980 e 1990 que aconteceram marcos importante para a história da saúde pública no Brasil, pois nesses anos emergiram grandes reviravoltas tanto no contexto histórico, cultural e sociológico que deram início a uma saúde justa para o cidadão. Porém, mesmo com todas essas modificações que são positivas a população em geral. Verificar-se que, no quadro atual, não é toda a população que têm acesso à saúde independente do lugar em que vive, sexo, idade, raça, etnia e situação sócio econômica. Mas, que o Sistema Único de Saúde vem trabalhando para melhorar essa situação. Visto que, SUS é um sistema de saúde em desenvolvimento que continua a lutar para garantir a cobertura universal e equitativa para a população (PAIM; TRAVASSOS; ALMEIDA, 2011). 


\section{REFERÊNCIAS BIBLIOGRÁFICAS}

BÍBLIA CATOLICA. Levítico. $2^{\circ}$ Ed. São Paulo: Editora SBB, 2010. Disponível em: <http://www.bibliacatolica.com.br/01/3/18.php>. Acesso em: 20 ago. 2017.

BRASIL.Ministério da Saúde. O Sistema Público de Saúde Brasileiro. Brasília - DF, 2006. Pag.: 1-44.

FARIA, Lina Rodrigues de. Os Primeiros Anos da Reforma Sanitária no Brasil e a Fundação Rockerfeller(19151920).Revista de Saúde Coletiva- Physis. Rio de Janeiro.Vol.5,nº1, p.109-129, 1995.

FINKELMAN, Jacobo. (Org.). Caminhos da saúde pública no Brasil. / Organizado por Jacobo Finkelman. Rio de Janeiro: Editora FIOCRUZ, 2002, Pag.:328.

JUNIOR, Aylton Paulus, JUNIOR, Luiz Cordoni. Políticas Públicas de Saúde no Brasil. Revista Espaço para a Saúde, Londrina, v.8, n.1, p.13-19, dez.2006. pag:13-19.

LAKATOS, Eva Maria, MARCONI, Marina de Andrade. Metodologia Científica. $1^{\text {a}}$ ed. São Paulo: Atlas, 1982.

MATOS A.; B.; SANTO, C. W. dos. A Saúde Pública no Brasil: Historicidade da Participação Popular e Evolução Jurídico-Constitucional para a Gestão de um Novo Modelo. P.3 s.n.t.. Disponível em:< http://www.viajus.com.br> . Acesso em: 22/08/2012.

MINISTÉRIO DA SAÚDE. ABC do SUS - Doutrinas Princípios. Brasília/DF 1990. Pag.: 6

MINISTÉRIO DA SAÚDE. Evolução Institucional da Saúde Pública. Brasília. 1979. pag: 1

MINISTÉRIO DA SAÚDE. O Sistema Público de Saúde Brasileiro. Brasília - DF, 2002. Pag.:13.

MORESI, E. (Organizador), Metodologia de Pesquisa, Universidade Católica de Brasília, 2003, 108 p.

MOTA, A.; SCHRAIBER, L. B. Atenção Primária no Sistema de Saúde: debates paulistas numa perspectiva histórica. Saúde Soc. São Paulo, v.20, n.4, p.837-852, 2011. Pag.: 837-852.

PAIM, Jaimilson; TRAVASSOS, Claudia; ALMEIDA, Célia. Saúde no Brasil 1:0 sistema de saúde brasileiro: história, avanços e desafios. Rev. Séries Saúde no Brasil, Salvador, v. 1, n. 1, p.1-21, maio 2011.

POLIGNANO, M. V. Historia Da Saúde Publica no Brasil: uma pequena revisão. Historia Das Politicas de Saude No Brasil, Minas Gerais, n. , p.01-25, 31 out. 2006. Disponível em:<http://internatorural.medicina.ufmg.br/saude no brasil.rtf. 2008.>. Acesso em: 02/06/2012.

RIZOTTI, M. L. A. Estado e Sociedade Civil na História das Políticas Sociais Brasileiras. Semina: Ci. Soc. Hum., Londrina, $\quad$ v. $22, \quad$ p.39-56, $\quad$ set. $2001 . \quad$ Disponível em: <http://www.uel.br/proppg/portal/pages/arquivo/pesquisa/semina/pdf/semina2212129.pdf> Acesso em: $02 / 07 / 2012$

SILVA, L. J. da. Revista de Saúde Pública: 30 anos de evolução. Revista de Saúde Pública, São, v. 06, n. 30, p.503-505, dez. 1996.

SOUZA, R. R. O Sistema Público de Saúde Brasileiro. Ministério da Saúde. São Paulo, Brasil, 2002. Pag.: 1- 45.

WALDMAN, E. A. Vigilância em Saúde Pública. volume 7 / Eliseu Alves Waldman ; colaboração de Tereza Etsuko da Costa Rosa. - São Paulo: Faculdade de Saúde Pública da Universidade de São Paulo, 1998. - (Série Saúde \& Cidadania). Pag.:1-2 